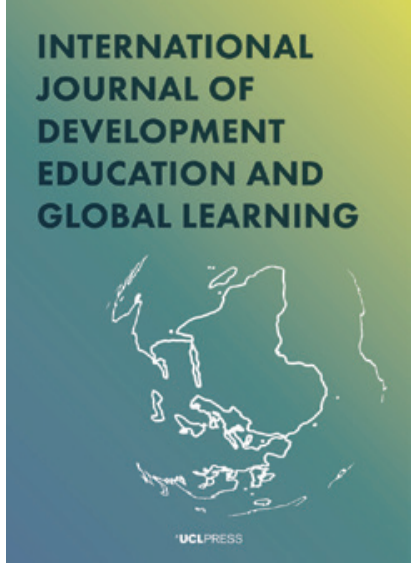

${ }^{\star}$ UCLPRESS

\section{INTERNATIONAL JOURNAL OF DEVELOPMENT EDUCATION AND GLOBAL LEARNING}

e-ISSN: $1756-5278$

Journal homepage:

https://www.uclpress.co.uk/pages/international-journalof-development-education-and-global-learning

\title{
Book review: Leadership and Power in International Development: Navigating the intersections of gender, culture, context, and sustainability, edited by Randal Joy Thompson and Julia Storberg-Walker
}

Shea N. Kerkhoff(D)

\section{How to cite this article}

Kerkhoff, S.N. (2020) 'Book review: Leadership and Power in International Development: Navigating the intersections of gender, culture, context, and sustainability, edited by Randal Joy Thompson and Julia Storberg-Walker'. International Journal of Development Education and Global Learning, 12 (1): 84-88. https://doi.org/10.14324/ IJDEGL.12.1.07

Submission date: 11 January 2019

Acceptance date: 5 December 2019

Publication date: 30 June 2020

\section{Peer review}

This article has been through editorial review.

\section{Copyright}

(C) 2020 Kerkhoff. This is an Open Access article distributed under the terms of the Creative Commons Attribution Licence, which permits unrestricted use, distribution, and reproduction in any medium, provided the original author and source are credited.

\section{Open access}

International Journal of Development Education and Global Learning is a peer-reviewed openaccess journal. 
Kerkhoff, S.N. (2020) 'Book review: Leadership and Power in International Development: Navigating the intersections of gender, culture, context, and sustainability, edited by Randal Joy Thompson and Julia Storberg-Walker'. International Journal of Development Education and Global Learning, 12 (1): 84-88. DOI https://doi.org/10.14324/IJDEGL.12.1.07

\section{Book review}

Shea N. Kerkhoff* - University of Missouri-St Louis, USA

Leadership and Power in International Development:

Navigating the intersections of gender, culture, context, and sustainability, edited by

Randal Joy Thompson and Julia Storberg-Walker

Bingley: Emerald Publishing; 2018; 368 pp; ISBN: 978-1-78754-116-0 (pbk);

ISBN: 978-1-78743-999-3 (ebk)

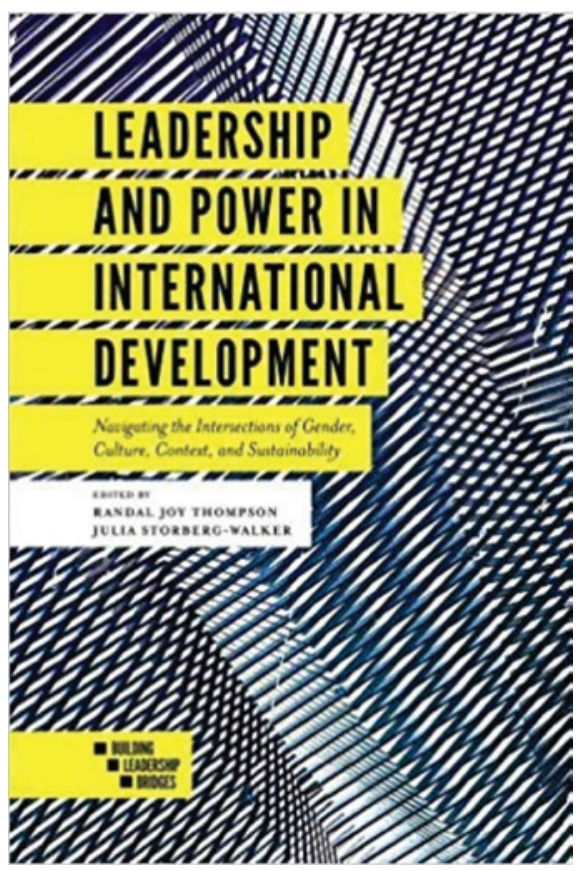

In 2015 the United Nations (UN) put forth a call to action on 17 Sustainable Development Goals (SDGs). In order to achieve these goals by 2030, education, health and economic development leaders will need to work together to solve the global challenges and improve life for all citizens of the world. How to lead these global efforts has become a question of renewed importance since the UN's call. Randal Joy Thompson, international development professional, and Julia StorbergWalker, Associate Professor of leadership at George Washington University, began a dialogue to answer this question in their book Leadership and Power in International Development: Navigating the Intersections of Gender, Culture, Context, and Sustainability. As is apparent from the title, this edited volume explores leadership in international development through a culturally and critically conscious lens. The book offers sage advice from diverse leaders on the ground, including those traditionally marginalized in leadership scholarship such as women and those from the Global South, as well as theoretical insight from a bird's-eye view. The volume is aimed at 
scholars of international development, junior and senior leaders in development and students of international education, health and economic development.

In order to contribute to practice and theory, the editors structure the book in a unique way. First is Thompson's overview and then a second overview by one of the contributors. Next, Storberg-Walker describes a qualitative content analysis of the chapters written by contributors. The following 17 chapters are organized into 5 parts: (1) challenges in international development; (2) leadership for women's empowerment and equity; (3) spirit-filled grassroots efforts; (4) leading major donor projects; and (5) leadership lessons to reflect on.

The volume begins with an introduction by Thompson, which includes the purpose and organization of the book, key terms and a brief history of the field. Thompson provides the definition of a leader in international development as 'a change maker dedicated to transforming complex systems and their components in developing countries (and by implication in the global world) such that all individuals in the world can live in equitable societies, free from want, able to achieve their aspirations, and in harmony with the environment' (3). Thompson's history begins with the conclusion of World War II and the creation of international organizations, such as the International Monetary Fund, the World Bank and the UN, for the purpose of economic growth in underdeveloped areas. In the 1960s, Thompson credits the need for a new kind of international development based on the independence of European colonies. She describes the rise of neoliberalism in the 1980s, which focused on market-driven policies and increased privatization.

The history takes the reader up to the current 'operating paradigm' of sustainable development (9). Today, international development donors include nongovernment organizations, private foundations and corporate responsibility programmes. In response to criticism of international development over the years, Thompson states, 'One of the hopes of this volume is that we will be able to offer leaders in international development a self-reflexive approach to leading that positively impacts the transformation of the global system and sincerely improves the lives of all peoples' (11).

Next, Anne Spear, who also authors Chapter 7, begins the second overview by commenting on neoliberal agendas and colonialist ideologies in international development. Spear describes how, as a whole, the chapter authors investigate their 'on-the-ground lived experiences' through the lens of culture and power, and take the critiques further by demonstrating successful projects (23). Her overview establishes the critical lens for the rest of the book.

Before each author shares their stories in Chapters 2-18, Storberg-Walker provides a qualitative analysis of those chapters. Looking across the diverse leaders' experiences for patterns, she offers three themes that cut across international development leadership experiences: power, connecting and paradox. Surrounding these three themes are how gender, culture and ongoing learning affect the ways in which power, connecting and paradox are performed. This qualitative analysis weaves in previous scholarship and new insights together with practitioner voices in a novel and interesting way to move towards a new theory of leadership that those in development education can use as a teaching framework.

The element of power acknowledges how privilege and status impact on the work that leaders are doing in the field. The theme is fluid: for example, one's gender can give a leader privilege in one instance and marginalize a leader in a different situation. Connecting indicates that leaders are always forming relationships based on respect and dignity. At the same time, they are working towards an end goal and 
need connections to make the work happen. Leaders in this volume share how the connections they made were strategic, based on skills and values, and not on skills or interest alone. The third theme is paradox. Storberg-Walker asserts that paradox is the next wave in leadership theory. Those who lead in international development endeavours and those in development education must navigate the tensions between local and global, short and long term, beneficiaries and donors, and neutral and political stances. Doing so requires the ability to handle cognitive complexity and crosscultural conflict management. This book offers a useful collection of lived experiences in navigating these tensions.

Each of the contributors presents a unique perspective, while the qualitative analysis of the chapters gives a holistic view of leadership in international development. The analysis also contributes to theory, with implications for future research to investigate whether the theory is indeed viable. As Storberg-Walker states, 'research on the "why me" of leading could focus on leader identity development across cultures and projects, taking into account power, connecting, and paradox' (50). Thus, the three elements of international development leadership provide a frame for future scholarship.

The chapters following the analysis discuss gender, culture, context and sustainability in international development theory in the voices of the leaders. The symphony of voices adds value to the volume, as readers hear straight from the source. Each has an original story to share and a distinctive way of doing so. Some chapters include poetry, others proverbs. Authors include women and men from sub-Saharan Africa, Indonesia, Europe, New Zealand, the United States and Canada. Notably missing from the book are voices from Latin America, North Africa and the Middle East and other parts of Asia. These leaders tell of their challenges, successes and hopes for the future across locations, including sub-Saharan Africa, North Africa, the Middle East, South Asia, Southeast Asia, Eastern Europe, Ecuador and New Zealand. The authors share personal theories of leadership, such as multidimensional, grassroots, accompaniment and feminine approaches. They share their vulnerabilities, their mistakes and lessons learned, demonstrating leadership while writing about it. As stated in Chapter 1: 'The authors are generously giving of themselves and sharing their experiences to help the rest of us continue to learn' (29). They write courageously and critically, such as when Obasanjo asserts, when speaking of outside donors, 'If elected officials in Third World countries cannot respond to their own local problems but only the problems as perceived and financed by the West, then we cannot solve our own problems but only solve problems the West deems important' (76).

Part I of the book titled 'Challenges in international development' includes four chapters that explain how leaders have navigated the tensions of respecting local culture and donor wishes, while also challenging cultural practices that are unjust or donor ideas that are unwise. One major takeaway is summed up by Ubalijoro when she says in Chapter 3: 'culture eats strategy for breakfast' (94). While we can work toward a theory of leadership in international development, as this book does, the theory itself must be dynamic, able to shift and change, as each person's power to create positive change determines the culture in which the work is taking place.

The female authors in Part II 'Leadership for women's empowerment and equity' discuss how they overcame sexism within the field and how they used the field to help empower women. Of note in these two sections are Ubalijoro's and LackovishVan Gorp's use of 'positive deviance' as a research strategy. Positive deviance is the study of a person who defies the odds and becomes successful, despite the numerous barriers in a community. As Ubalijoro asserts, 'Studying and dissecting poverty doesn't 
create a pathway to prosperity but serves to nurture experts on poverty' (92). Instead of creating scholarship on the barriers, like poverty, these two women identified successful community members and studied the positive.

Part III tackles international development through a spiritual lens, including two chapters that discuss partnerships between education and faith-based organizations. The authors in Part IV share their experiences working with large donor agencies. McLaughlin describes her work in education with USAID and country-level ministries of education, and closes with these thoughts: 'Among the most valuable leadership lessons I have learned is the importance of self-awareness and self-reflection. Awareness of how I am perceived by others helps me relate effectively and knowing what gives me purpose to my work helps me find joy in it' (275-6). Her ability to reflect helps her to understand how others see her and keeps her purpose in the forefront of her mind, which leads to the last section of the book.

Part $V$ is titled 'Leadership lessons to reflect on' and invites readers to consider their own leadership. Overall, the book provides insights from experienced leaders that can help practitioners and scholars across development fields and locations to practise culturally sensitive and critically conscious leadership. Leadership and Power in International Development: Navigating the intersections of gender, culture, context, and sustainability is a worthwhile resource that tells the stories of international development leaders and puts forth a theory based on the narratives.

The editors seem to be working from the premise that, whether we like it or not, international development is happening and, as such, we can do international development work better by prioritizing the voices of women and those from the Global South. The editors chose contributors to increase the diversity of voices found in the fields of international development and leadership. They criticize the fields as being 'Western-focused, gender biased, and replete with normative values' (29). However, Thompson, Storberg-Walker and Spear - those who edited and provided commentary on the contributions - all seem to be white American women. As such, the book may indeed challenge gender bias but perhaps falls short of challenging the Western-focus tradition.

Gender was explicitly mentioned in the call for chapters, and many of the contributors dissect and analyse gender in Part II, which focuses on sexism, as well as the other chapters. By including 14 chapters written by women leaders, and by making gender explicit in the call for chapters, in Part II and in its title, the book achieves the goal of including the under-researched area of gender in international development research.

However, the book offers only seven chapters written by authors from (or whose families are from) the Global South. While these chapters contribute diverse perspectives to the literature, the qualitative analysis of these chapters was conducted by a Westerner after a revision process undertaken with the first editor, also a Westerner. Thus, the reader must be cognizant that even though the focus may not be on Western countries, the values illustrated may still come from a Western perspective. I acknowledge that trying to capture a viewpoint from every region of the globe is difficult to do in a single work, and it would seem that conducting the qualitative analysis on the authors' first drafts may have helped limit Western bias. From a postcolonial theoretical perspective, merely doing work in traditionally marginalized communities is not enough. Authors must also reflect on their political power and positionality as cultural outsiders when appropriate (Ndimande, 2018). As a whole, the book does a better job of reflecting on and analysing gender than it does culture. 
This book would be of interest to scholars of leadership, international development and development education. The content lays out what leaders need to know, understand and be able to do in international contexts. However, in addition to the content, the structure of the book contributes a model for collaboration between practitioners and researchers, and serves as an example of grounded theory work where the data (i.e. the leadership stories), methods and findings are shared. Thus, the book is also a valuable resource for students of qualitative methods in development education research. As development leaders work towards the UN's SDGs, this book offers wisdom in how to make productive connections and enact successful strategies based on power relationships in diverse settings.

\section{Notes on the contributor}

Shea N. Kerkhoff is Assistant Professor in the College of Education at the University of Missouri-St Louis. She holds a PhD from North Carolina State University in Curriculum and Instruction. Kerkhoff utilizes mixed methods to investigate critical, digital and global literacies. She also serves as the Education Director of Going Global, Inc. She has worked in Kenya, India, Belize, Guatemala, China, Myanmar and the United States. In 2018, she was named a Longview Foundation Global Teacher Educator fellow.

\section{Reference}

Ndimande, B.S. (2018) 'Unraveling the neocolonial epistemologies: Decolonizing research toward transformative literacy'. Journal of Literacy Research, 50 (3), 383-90. 